\title{
Desenvolvimento de Artefatos Digitais Educacionais com Estudantes de Ensino Fundamental da Educação do Campo
}

\author{
Dyego Carlos Sales de Morais ${ }^{1}$, Taciana Pontual Falcão ${ }^{2}$, Flávia Mendes de \\ Andrade e Peres ${ }^{3}$, Patrícia Cabral de Azevedo Restelli Tedesco ${ }^{1}$ \\ ${ }^{1}$ Centro de Informática - Universidade Federal de Pernambuco - Recife, PE \\ ${ }^{2}$ Departamento de Computação - Universidade Federal Rural de Pernambuco - Recife, \\ PE \\ ${ }^{3}$ Departamento de Educação -Universidade Federal Rural de Pernambuco - Recife, PE \\ moraisdcs@gmail.com, taciana.pontual@ufrpe.br, peres.flavia@gmail.com, \\ pcartecin.ufpe.br
}

\begin{abstract}
This report presents educational digital artifacts produced within the DEMULTS project, which applies Participatory Design in the context of Rural Schools. This context demands participation of people who live in rural areas in the production of educational resources and digital artifacts. For this reason, the artifacts are developed collaboratively by students, agroecology practitioners and researchers from the computing, education and design fields. The artifacts address sugarcane harvest and off-season, recycling, composting and organic garden cultivation. Participatory Design proved to be useful as a strategy for democratizing the design and development process of such artifacts.
\end{abstract}

Resumo. Este relato apresenta artefatos digitais educacionais produzidos no âmbito do projeto DEMULTS-Campo, que aplica Design Participativo no contexto da Educação do Campo (EdC). A EdC demanda por participação de sujeitos do campo na produção de materiais didáticos e artefatos digitais. Por isto, os artefatos foram desenvolvidos colaborativamente por estudantes, técnicos de agroecologia e pesquisadores de computação, educação e design, abordando temáticas relativas a safra e entressafra de cana-de-açúcar, reciclagem, compostagem e cultivo de horta orgânica. O Design Participativo se mostrou proveitoso enquanto estratégia de democratização do processo de design e desenvolvimento de tais artefatos.

\section{Introdução}

O movimento por uma Educação do Campo (EdC) surge a partir da reivindicação das pessoas que constituem os povos do campo (assentadas, pequenas agricultoras, ribeirinhas, entre outras) por uma educação no local onde vivem, mas principalmente que leve em consideração a participação delas na prática educacional, vinculada aos seus cotidianos e às necessidades humanas e sociais dos sujeitos campesinos [Caldart 2004]. Com essas motivações, este movimento (que abarcou diversos outros movimentos pela reforma agrária) conquistou políticas públicas específicas para viabilidade institucional dessa prática educacional, como as diretrizes curriculares e o PRONERA (Programa Nacional de Educação na Reforma Agrária).

Apesar disso, tanto tecnologias digitais quanto materiais didáticos, utilizados em escolas de Educação do Campo, ainda são produzidos fora dos contextos camponeses, sem a legítima participação de seus representantes [Molina 2014, Ortiz \& Pereira 2019]. 
A problemática dos materiais didáticos serem produzidos por grandes editoras em centro urbanos e apenas importados para as escolas do campo, sem a devida participação para a contextualização cultural e social local, já possui um certo espaço nas discussões sobre Educação do Campo [Molina 2014, Rocha 2014, Silva et al. 2017]. No entanto, os trabalhos que versam sobre tecnologias digitais na Educação do Campo tratam majoritariamente do seu uso e não incluem o desenvolvimento com participação de estudantes, seus responsáveis legais, docentes e gestores [Santos \& Leão 2017].

Visando atender a essas demandas, o projeto DEMULTS (Desenvolvimento Educacional de Multimídias Sustentáveis) teve seu processo de desenvolvimento participativo de tecnologias digitais educacionais (até então realizado em contextos urbanos) adaptado para o contexto campesino [Morais et al. 2021]. O DEMULTS-Campo aplica a metodologia do Design Participativo, visando envolver representantes do público-alvo na tomada de decisão da concepção de artefatos como forma de atender as demandas da EdC. No presente relato, são apresentados os artefatos gerados no ciclo de pesquisa-ação realizado entre 2019 e 2020 no contexto de EdC no contraturno escolar de duas escolas do campo do município de Vicência-PE. O documento está organizado em quatro seções, além desta: primeiro, apresenta-se o conceito de EdC e suas demandas; em seguida, é apresentada a metodologia do projeto DEMULTS-Campo, sua base teórica e os contextos de intervenção; então, são apresentados os artefatos gerados a partir da intervenção; por fim, são feitas as considerações finais e apresentadas oportunidades de trabalhos futuros.

\section{Tecnologias Digitais e Materiais Didáticos para Educação do Campo}

O fenômeno da Educação do Campo (EdC) no Brasil é protagonizado por pessoas trabalhadoras, movimentos sociais e organizações do campo, que reivindicam o direito à educação no local onde estão inseridos e com o propósito de corroborar para sua formação enquanto sujeitos do campo. Para isto, as escolas e iniciativas vinculadas à EdC buscam entrelaçar conteúdos curriculares dos diversos níveis de ensino às "questões do trabalho, da cultura, do conhecimento e das lutas sociais dos camponeses e ao embate (de classe) entre projetos de campo e entre lógicas de agricultura que têm implicações no projeto de país e de sociedade e nas concepções de política pública, de educação e de formação humana" [Caldart 2012, p. 259].

$\mathrm{O}$ vínculo com a cultura camponesa, explicitado nas diretrizes da EdC, somado às necessidades de uma educação contextualizada aos povos do campo, que demandam participação desses sujeitos desde a concepção do fenômeno educacional até o cotidiano escolar, corrobora para emergência de reivindicações também por materiais didáticos que contemplem a realidade do campo. Em 2013, a partir dessas reivindicações foi instituído o Programa Nacional do Livro Didático para EdC (PNLD-Campo), com o objetivo de produção e distribuição de livros contextualizados para o território campesino. No entanto, o programa, extinto em 2018, abrangia apenas os anos iniciais do Ensino Fundamental, com livros feitos por grandes editoras sem participação dos sujeitos do campo [Molina 2014] e conteúdos insuficientemente contextualizados para a vida no campo [Rocha 2014, Silva et al. 2017].

Em paralelo a esta demanda, para além da EdC, a discussão das tecnologias digitais na educação vai desde a concepção até o seu uso crítico. Na BNCC (Base 
Nacional Comum Curricular), consta como competência geral, que além de acesso e compartilhamento de informações para compreensão e uso de tecnologias digitais, é preciso que estudantes sejam capazes de construir tecnologias digitais "de forma crítica, significativa, reflexiva e ética nas diversas práticas sociais (incluindo as escolares) para (...) produzir conhecimentos, resolver problemas e exercer protagonismo e autoria na vida pessoal e coletiva" [Brasil 2017].

No âmbito da EdC, os trabalhos sobre tecnologias digitais ainda versam majoritariamente apenas sobre o uso [Munarim 2014, Santos \& Leão 2017]. Neste sentido, Munarim (2014) questiona se os projetos de inclusão digital na EdC visam "contribuir para fortalecer a luta por um outro projeto de campo, mais justo, mais solidário, em que a agricultura familiar, os povos do campo, seus territórios e saberes, sejam legitimados e levados a sério nas políticas públicas do país" [Munarim 2014, p. 168], ou se apenas repetem acriticamente discursos modernizantes que ampliam as diferenças entre campo e cidade, sem considerar o campo como um espaço de vida.

Dentro desse debate e motivados pela BNCC, pontuamos a importância de tais projetos não apenas importarem e consumirem tecnologias digitais educacionais feitas em centros urbanos, mas de promoverem equidade de acesso ao conhecimento e de oportunidades entre campo e cidade, envolvendo sujeitos do campo desde a concepção e o desenvolvimento de tais tecnologias para a EdC. Nesse sentido, em sucessivos ciclos de pesquisa-ação, a partir da aplicação de metodologias participativas, temos aprimorado o processo de desenvolvimento de artefatos digitais educacionais com estudantes de escolas do campo. O processo empregado para tal é apresentado a seguir.

\section{DEMULTS-Campo}

O projeto DEMULTS-Campo ocorre em ciclos de pesquisa-ação, baseados na metodologia do Design Participativo [Spinuzzi 2005], por meio da qual estudantes de escolas do campo, enquanto representantes do conjunto de potenciais utentes de artefatos digitais educacionais, são envolvidos no processo de desenvolvimento como co-participantes. No presente relato, apresentamos os artefatos gerados a partir do último ciclo realizado entre Agosto de 2019 e Março de 2020 no município de Vicência, localizado na Zona da Mata de Pernambuco. Vicência possui vínculo histórico com o corte de cana-de-açúcar, inclusive tendo o caule em seu brasão e sendo até hoje circundado de terrenos com seu plantio, feito majoritariamente por usinas. As duas escolas locus, inseridas em terrenos de usinas de cana (uma ativada e outra desativada), foram escolhidas em diálogo com a Secretaria de Educação do município, com base no seu alinhamento com as diretrizes da EdC, e sua proximidade a rodovias para possibilitar aplicação do ciclo em duas escolas (cada uma em um turno).

O processo de desenvolvimento se deu a partir da seleção de 50 estudantes de Ensino Fundamental II (do sexto ao nono ano) indicados pelas coordenações das escolas, levando em consideração critérios de diversidade de gênero, de rendimentos escolares e comportamentos com vários níveis de compatibilidade com as regras de funcionamento do ambiente escolar. Estudantes das duas escolas possuíam familiares com parcelas de terras, que eram áreas conquistadas por meio de ocupações e assentamentos de movimentos sociais pela reforma agrária. As famílias utilizam parcelas para moradia e cultivo, algumas para plantação de hortaliças e tubérculos, 
outras para cana-de-açúcar a fim de revender para a usina. A maioria dos estudantes possuía saberes sobre plantação e cultivo que os pesquisadores não possuíam.

Além dos estudantes, participaram do processo três técnicos em agroecologia, que já possuíam atuação com hortas orgânicas e compostagem nas escolas do município, e favoreceram mediações sobre conhecimentos em agroecologia, e outros conteúdos curriculares explorados em cada artefato. Os técnicos faziam a transposição didática, ora para os estudantes, que possuíam os saberes construídos a partir de suas experiências, mas com algumas lacunas em relação aos termos e conceitos científicos e curriculares desses saberes; ora mediando os saberes dos estudantes para os pesquisadores do DEMULTS-Campo. As pessoas pesquisadoras colaboraram com os saberes computacionais e de design, necessários para desenvolvimento de artefatos digitais. Desse modo, estudantes, técnicos e pesquisadores co-criaram jogos e aplicativos educacionais, interagindo em todas as etapas desde a decisão sobre temáticas da agroecologia até o desenvolvimento no Scratch ou App Inventor.

Os encontros aconteciam duas vezes por semana no contraturno dos estudantes, inicialmente na escola, nas etapas que não precisavam de computadores. Posteriormente, nas etapas que precisavam de computadores (em especial a de produção com design e programação dos artefatos), os encontros ocorreram em um local no perímetro urbano do município reservado para cursos de diversas secretarias. A partir da parceria com a Secretaria de Educação do Município, devido às escolas não possuírem computadores suficientes, utilizamos este local, denominado de condomínio de cursos. No entanto, a pequena sala disponibilizada não possuía ar-condicionado, causando muito desconforto a todas as pessoas por conta do calor excessivo. Além disso, nem todos os computadores estavam funcionando ou acessando a internet. Por isso, em vários momentos, optamos por utilizar equipamentos pessoais em outras salas maiores e mais arejadas do condomínio. O processo implementado neste ciclo possui as etapas exibidas na Figura 1 e descritas a seguir.

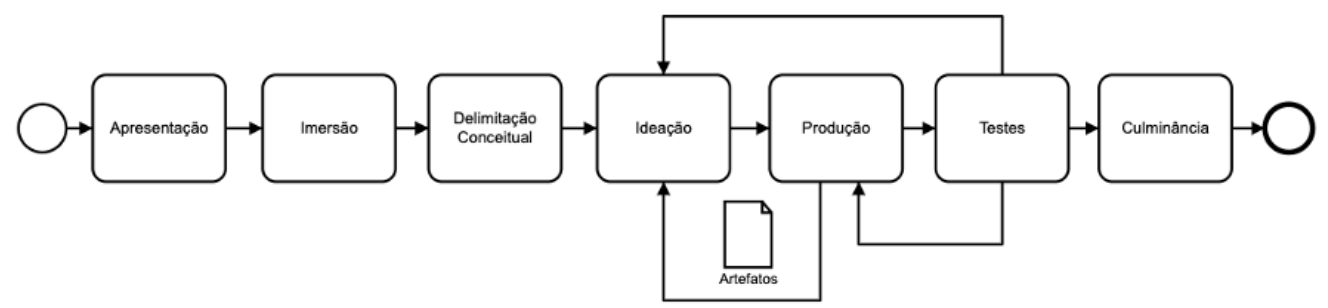

Figura 1. Etapas do processo de desenvolvimento de artefatos digitais educacionais na EdC.

- Apresentação, em que é feita uma roda de diálogo para apresentar o projeto e saber o que os estudantes esperam aprender durante o processo; seguida por uma dinâmica de grupo para apresentação de cada participante; e um braindraw sobre tecnologia no cotidiano dos estudantes (técnica participativa, tal qual o brainstorm, mas usando desenhos). Nesta etapa é entregue o termo de consentimento para que os responsáveis legais pelos estudantes assinem.

- Imersão, em que, com o objetivo de irem se familiarizando com elementos de jogos como roteiro, narrativa, mecânica, regras, desafios e recompensas, 
os estudantes, em grupos, produzem uma história em quadrinhos sobre aspectos do seu cotidiano, como se eles fossem o personagem principal de um jogo. Além disso, nessa etapa, com o objetivo de conhecer o contexto do território e da história de vida dos estudantes e de seus familiares, constrói-se com eles um roteiro de entrevistas, para que realizem com seus responsáveis.

- Delimitação conceitual, em que se realiza um brainstorm sobre a relação entre os aspectos do cotidiano dos estudantes identificados na etapa de imersão, e temáticas ou práticas que fortalecem a EdC. Essa interseção permite delimitar os conceitos e práticas campesinas que serão abordados nos artefatos digitais didáticos nas próximas etapas.

- Ideação, em que, a partir de pesquisas com o apoio dos técnicos em agroecologia e dos pesquisadores, definem-se o roteiro e a narrativa dos artefatos com novas histórias em quadrinhos.

- Produção, em que, com a narrativa definida, parte-se para o desenvolvimento dos artefatos didáticos digitais, utilizando as ferramentas de design e programação. As artes são criadas pelos estudantes designers e integradas aos jogos, que são desenvolvidos pelos estudantes programadores, por meio de integração de componentes programados por terceiros ou programados com blocos por eles mesmos; algumas vezes é necessário adaptar as histórias idealizadas, seja por limitação de tempo para conclusão do artefato, seja por limitação da ferramenta de programação em blocos.

- Testes, em que, visando uma validação, bem como possíveis melhorias, são realizados testes informais dos jogos, nos quais os usuários (estudantes da mesma escola, mas que não participaram do projeto) falam o que pensam no momento do uso dos artefatos.

- Culminância, em que os estudantes apresentam seus produtos para comunidade escolar, incluindo professores, gestores, mães, pais e responsáveis.

Um diferencial do processo é não haver aulas expositivas sobre design, programação ou agroecologia, o que fomenta a interação entre todos os participantes, culminando em uma aprendizagem mútua sob demanda. Por meio deste processo, foram desenvolvidos protótipos de um aplicativo Android (usando AppInventor) e cinco jogos educacionais (usando Scratch) que envolvem desde compostagem, reciclagem e criação de horta orgânica, até equipamentos de proteção individual (EPI) e outras questões relacionadas ao corte da cana-de-açúcar na safra e ao cultivo de outras plantações na entressafra. Os testes e a culminância não foram executados no ciclo aqui apresentado devido à pandemia do novo coronavírus, que interrompeu os encontros presenciais, e aos estudantes não terem acesso a computadores com internet para continuidade das atividades remotamente. Os artefatos são detalhados a seguir.

\section{Artefatos Produzidos}

Apesar das escolas estarem ambas em territórios rurais do mesmo município, perceberam-se algumas diferenças entre elas, e em relação aos estudantes de cada uma, durante o processo de desenvolvimento dos artefatos. Na turma cujos encontros aconteceram no período da manhã, alguns estudantes possuíam experiência prática do corte de cana-de-açúcar e desistiram do projeto no período de safra do caule para trabalhar. Consequentemente, menos artefatos foram produzidos na manhã em 
comparação à turma da tarde. A turma da manhã produziu dois jogos, enquanto a turma da tarde produziu três jogos (dois dos quais se tornaram um único jogo durante o desenvolvimento) e um aplicativo.

Os dois jogos produzidos na turma da manhã foram pensados a partir dos períodos de entressafra (com plantio agroecológico), e de safra da cana-de-açúcar, (incluindo trabalho de corte para usinas), por proposta dos estudantes, em diálogo com os pesquisadores especialistas em programação e os técnicos em agroecologia. O jogo relacionado ao período da entressafra da cana-de-açúcar, em que há uma diminuição na produção do caule e as famílias tendem a tirar seu sustento da plantação que possuem em sua parcela de terra, tem o nome de A Fazenda Escondida (Figura 2). O objetivo do jogo é limpar o canteiro para cultivo da horta (Figura 2, à direita), através do clique em cada círculo com mato: à medida que o jogador clica, vai retirando (apagando) os matos. Outras fases foram pensadas para esse jogo, desde o gerenciamento de moedas, até a compra de sementes e venda de produtos em feiras agroecológicas, mas ainda não foram desenvolvidas. Apesar dos estudantes deste grupo serem mais introspectivos ou desatentos que os do outro, eles possuíam saberes sobre a criação e manutenção de hortas orgânicas e o controle de pragas sem uso de agrotóxicos. Assim, os pesquisadores que estiveram mais ativamente auxiliando o desenvolvimento desse jogo tiveram contato com esses saberes previamente construídos pelos estudantes, e também pelos técnicos e pela coordenadora da escola.

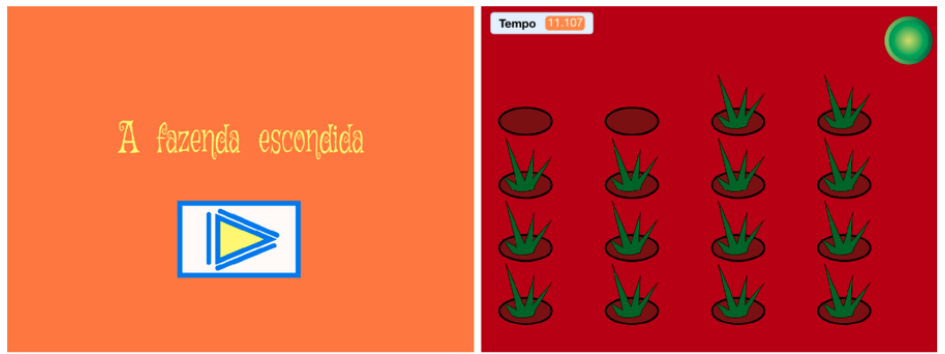

Figura 2. Telas de abertura (à esquerda) e limpeza de canteiro (à direita) do jogo A Fazenda Escondida.

$\mathrm{Na}$ narrativa do jogo relacionado à safra da cana-de-açúcar (que não foi nomeado), um cortador tenta negociar seu salário com o gestor da usina e expõe a injusta retribuição pelo árduo trabalho, enquanto os donos da usina enriquecem, conforme apresentado na Figura 3 (à esquerda). Em seguida, o jogo apresenta a queima das folhas da cana (realizada para facilitar o corte do caule). Após esta etapa, o jogador escolhe as EPI corretas e então assume o comando do personagem principal para realizar o corte da cana. $\mathrm{O}$ desafio imposto é cortar a maior quantidade de cana em um determinado tempo. O corte é feito clicando no cutelo (objeto cortante usado no corte da cana, representado como um retângulo verde na Figura 3, à direita) e levando o cursor do mouse, seguido pelo cutelo, até a cana. Na primeira vez que o cutelo toca a cana, ela é cortada do chão; na segunda vez, corta-se o olho da cana (folhas que crescem em cima do caule), direcionando-a até a esteira (fileira no chão). Após isso, o personagem volta para casa e cultiva sua horta com sua filha, que tem o sonho, e o realiza, de ser professora para ensinar outras pessoas a fazer hortas orgânicas (Figura 4). Esta etapa final não chegou a ser desenvolvida ainda e foi desenhada durante a etapa de produção. 

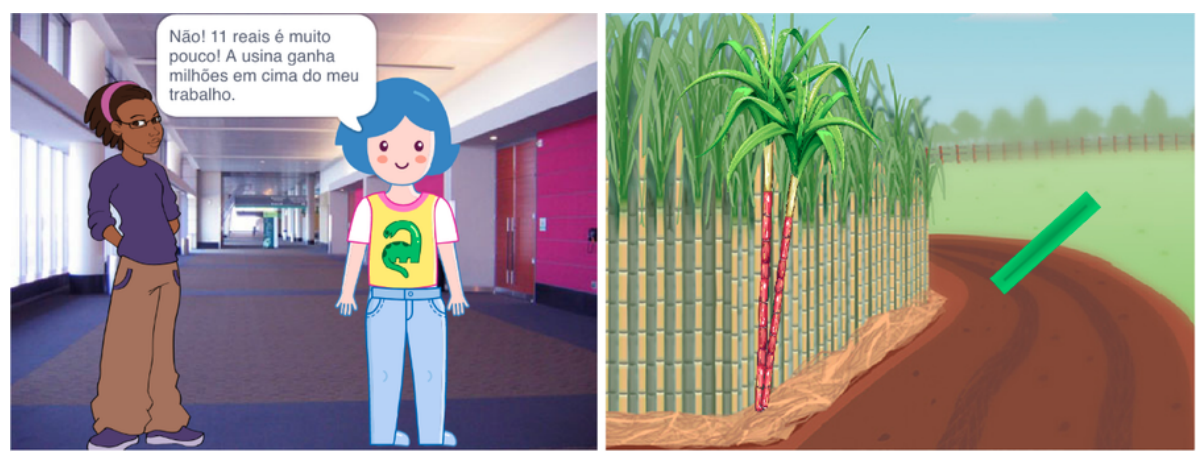

Figura 3. Telas de diálogo entre gestor da usina e cortador de cana ${ }^{1}$ (à esquerda) e do corte da cana (à direita) do jogo relacionado à safra de cana-de-açúcar.

A narrativa deste jogo resulta de uma ressignificação dos estudantes sobre suas concepções acerca do contexto socioeconômico que envolve o corte da cana-de-açúcar, que vivenciam desde muito jovens. Durante o processo de desenvolvimento do jogo, percebeu-se uma identificação dos estudantes com a dinâmica instaurada e até mesmo com a usina da cidade, reproduzindo a lógica do lucro dos donos de usina. Entretanto, a partir de pesquisas na internet e dos diálogos com os pesquisadores e os técnicos, os estudantes foram percebendo as injustiças presentes no salário do cortador, nos riscos à saúde dos trabalhadores quando se aplica agrotóxico, e na falta de EPI apropriados, além de perceberem que sem cortador não há nem usina, nem lucro para o patrão. Não só os estudantes foram transformados, mas os pesquisadores também adquiriram novas palavras do vocabulário referente à prática do corte da cana.

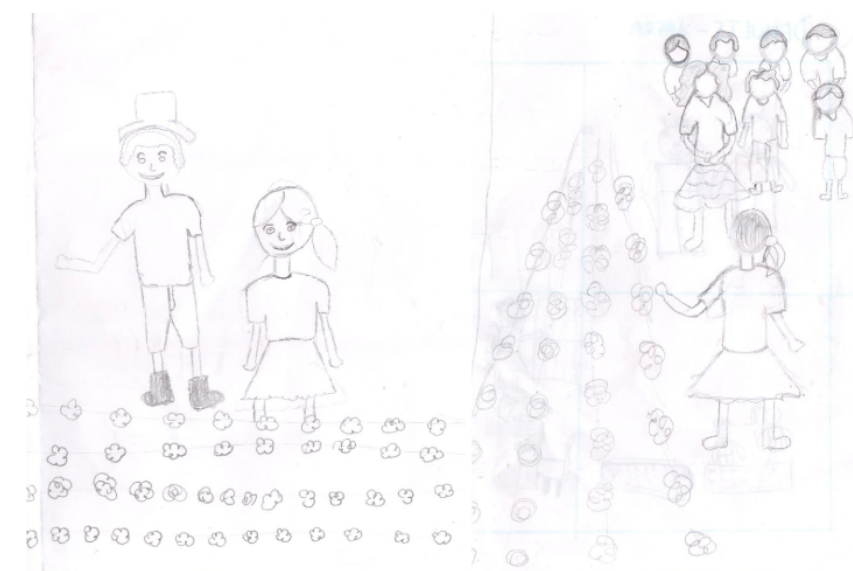

Figura 4. Desenhos das telas restantes do jogo relacionado à safra de cana-de-açúcar, em que o cortador de cana planta com sua filha na horta orgânica que possui em sua parcela de terra (à esquerda); e ela depois como professora ensinando estudantes sobre o cultivo de horta orgânica (à direita).

Os três jogos da turma da tarde tratavam sobre coleta seletiva de resíduos sólidos, bem como de sua reciclagem de tais resíduos. Como a temática era similar, antes de iniciar o desenvolvimento, foi feita uma assembleia com escuta de cada participante justificando o voto por unificar os três jogos ou mantê-los separados. A

\footnotetext{
${ }^{1}$ As imagens apresentam personagens femininas, pois foram escolhidas dentre as disponíveis no Scratch, sem levar em consideração gênero ou aparência, mas apenas para agilizar o desenvolvimento do protótipo, e serem substituídas na versão final. No caso da personagem que representa o cortador de cana (personagem à direita na Figura 3), levou-se em consideração a facilidade da troca da vestimenta por EPI.
} 
decisão foi por unificar as narrativas de dois jogos, que deram origem ao jogo Limpeza Play, e permanecer com o terceiro separado, que tornou-se o jogo EcoRural. Os dois grupos que se unificaram acordaram em unificar as narrativas, mas o desenvolvimento foi feito em separado, apesar de sempre haver ajuda mútua quanto à programação.

A história dos dois jogos unificados no Limpeza Play se inicia com o diálogo de duas vizinhas, uma que tem uma composteira e outra que faz coleta seletiva. Cada uma explica à outra como fazer o que faz e a importância de fazê-lo, conforme Figura 5 (à esquerda). Em seguida, aparecem cinco lixeiras e cinco resíduos para descarte correto (Figura 5, à direita). Usando o mouse, o jogador deve arrastar o resíduo A partir do clique no resíduo, o objeto segue o cursor do mouse e o usuário precisa levá-lo até o lixeiro correto. $\mathrm{O}$ usuário tem 3 vidas, caso erre perde uma vida.

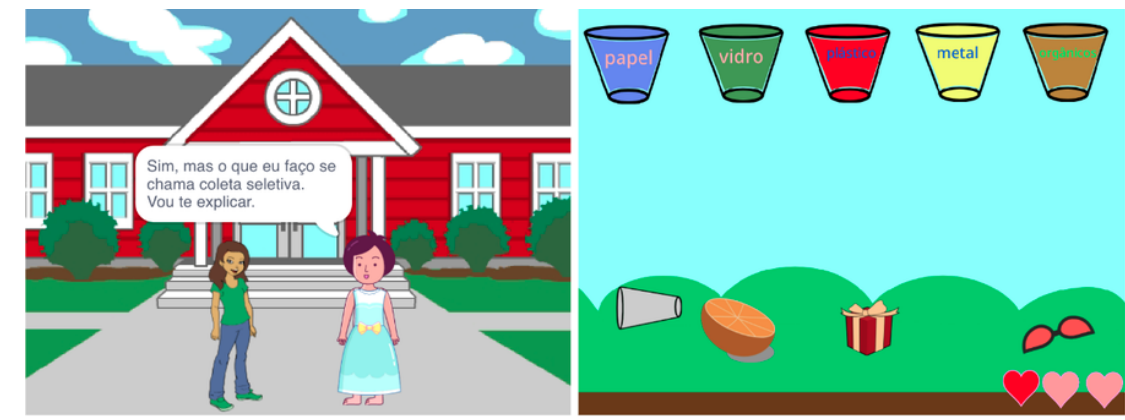

Figura 5. Telas de diálogo (à esquerda) e interação com usuário para coleta seletiva (à direita) do jogo Limpeza Play.

O Limpeza Play continua com outro diálogo, explicando os benefícios da compostagem, seguido de separação de resíduos orgânicos e inorgânicos. A separação ocorre clicando e arrastando os resíduos até uma das extremidades laterais da tela do jogo, conforme apresentado na Figura 6 (à esquerda). Em seguida, vem a fase de montagem da composteira com os materiais orgânicos (ainda por fazer). Depois disso, já foi desenvolvida a fase de cultivo da horta, em que o usuário clica nos espaços para cavar e plantar sementes, que crescem (Figura 6, à direita).
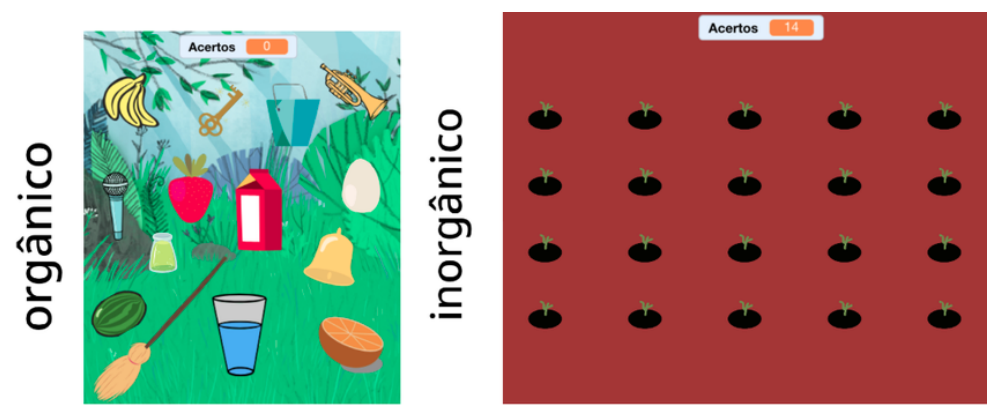

Figura 6. Telas de interação para separação entre resíduos orgânicos e inorgânicos (à esquerda) e plantio da horta orgânica (à direita) do jogo Limpeza Play.

O jogo EcoRural possui, na tela inicial, conforme apresentado na Figura 7 (à esquerda), um botão que direciona para a tela de informações que apresenta alguns detalhes sobre a compostagem, como por exemplo: cascas de frutas cítricas são orgânicas, mas não devem ir para composteira, pois alteram demasiadamente o pH da terra, prejudicando o processo, de acordo com texto produzido pelas estudantes do grupo com apoio dos técnicos em agroecologia. O jogo se passa numa fazenda 
abandonada, em que os antigos donos deixaram lixo espalhado, e o usuário tem como objetivo direcionar os resíduos para a composteira, para a alimentação de animais ou para a criação de objetos feitos de materiais reciclados para casa. Para isso, é perguntado se o resíduo é orgânico ou inorgânico, seguido da pergunta sobre qual o destino do resíduo (Figura 7, à direita). O usuário deve conseguir responder tudo em 60 segundos e tem três vidas, que são perdidas quando ele erra a resposta de alguma pergunta. A estudante que atuou como desenvolvedora do jogo avançou rapidamente nos conceitos de variáveis e condicionais, de modo que este jogo ficou pronto antes dos demais e ela prontamente auxiliou as programadoras do Limpeza Play.
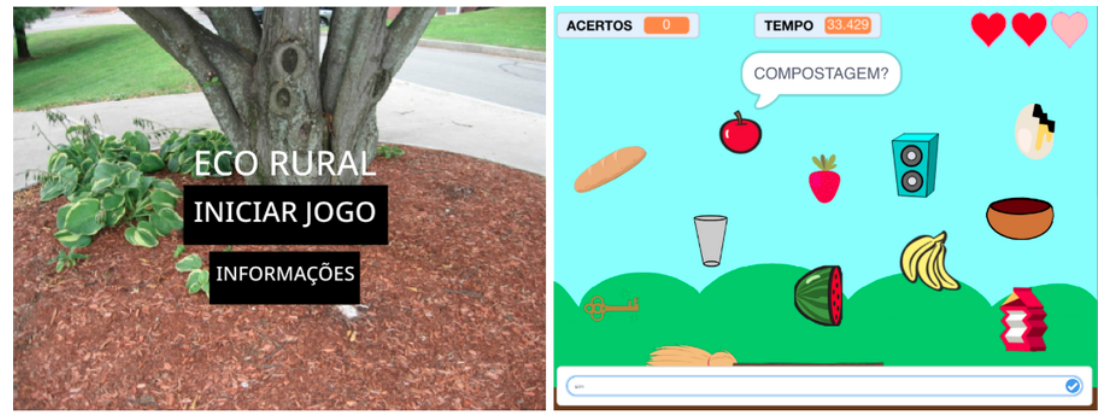

Figura 7. Telas de abertura (à esquerda) e interação com usuário para separação de resíduos (à direita) do jogo EcoRural.

Outro grupo pertencente à turma da tarde desenvolveu um aplicativo com o App Inventor. $\mathrm{O}$ aplicativo myHorta tem como objetivo auxiliar usuários que desejam criar uma horta agroecológica, incluindo preparação do local para plantação, cultivos de hortaliças, tratos culturais e controle de praga sem uso de agrotóxico, conforme menu apresentado na Figura 8 (à direita). Este grupo se envolveu de forma ativa na divisão de tarefas e condução do processo, demandando menos atenção dos pesquisadores para gestão de atividades. Os estudantes dividiram as atividades de design, programação e fichamento de um livro sobre o cultivo de hortas orgânicas.

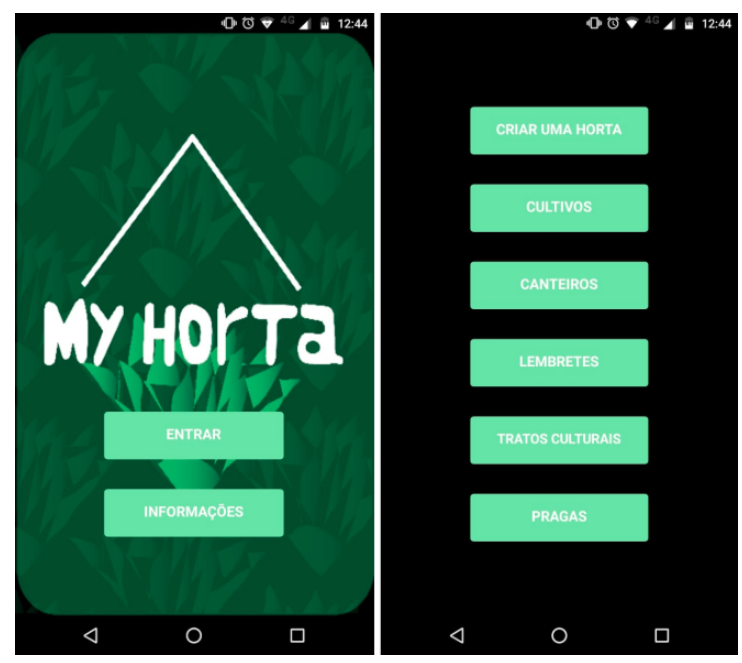

Figura 8. Telas de abertura (à esquerda) e menu (à direita) do aplicativo myHorta.

Os artefatos apresentam em suas interfaces parte essencial das trocas de saberes que ocorreram durante o processo de desenvolvimento entre estudantes, técnicos e pesquisadores. Na turma da manhã, os conteúdos escolhidos pelos estudantes que se 
tornaram centrais para os artefatos foram mais relacionados ao corte da cana-de-açúcar, acredita-se que devido à experiência prévia dos estudantes tanto do corte, quanto da cogestão da parcela. No entanto, no jogo da entressafra também houve troca em relação a produção agroecológica. $\mathrm{Na}$ turma da tarde, os saberes eram mais relacionados à reciclagem de resíduos sólidos, compostagem e cultivo de horta orgânica. As temáticas, narrativas e jogabilidade foram construídas em diálogo entre todos os participantes. Buscou-se, do início ao fim, partilhar o poder de tomada de decisão sobre os artefatos com os estudantes. Neste sentido, o Design Participativo mostrou-se apropriado ao contexto de EdC, atendendo às demandas de construção de materiais didáticos e tecnologias digitais com ênfase na participação dos estudantes de escolas do campo.

\section{Considerações Finais}

Este trabalho apresentou artefatos produzidos por estudantes do ensino fundamental no contexto da Educação do Campo. A EdC demandou atenção especial à participação dos estudantes, o que direcionou os pesquisadores para adoção do Design Participativo enquanto metodologia que permeou o processo de desenvolvimento. Os artefatos apresentados respondem à demanda de materiais didáticos contextualizados para EdC, ao mesmo tempo em que seu processo de desenvolvimento com base no Design Participativo aponta para um modelo em acordo com o projeto político-pedagógico da EdC, no qual os estudantes são coparticipantes do processo com poder similar aos pesquisadores e técnicos na tomada de decisão sobre os artefatos.

Outro destaque importante é a participação dos técnicos em agroecologia, que a cada novo conceito para os artefatos trazido por estudantes, mediavam o processo a fim de garantir a conformidade de tais saberes com conteúdos curriculares com a especificidade do território campesino. Entende-se que tal mediação também enriqueceu a troca de saberes e possibilitou um alinhamento pedagógico de fortalecimento da EdC.

As dificuldades encontradas são principalmente decorrentes da infraestrutura escolar, que não dispõe de computadores. Entendemos que para que escolas do campo tenham plena capacidade de desenvolver a competência de desenvolvimento de tecnologias digitais, conforme estabelece a BNCC, é preciso garantir que elas tenham os meios tecnológicos, como computadores e internet acessíveis aos estudantes. Apesar disso, com o objetivo de fortalecer a EdC no locus escolar, realizamos as etapas anteriores e posteriores à de produção nas escolas.

Em específico à participação dos estudantes no processo, pontua-se que mesmo em um contexto democrático, como o proporcionado pelo projeto aqui apresentado, alguns estudantes assumem maior autonomia e papéis de maior protagonismo, enquanto outros sentem dificuldade de interagir e se engajar, seja por questões pessoais de personalidade mais introspectiva ou baixo interesse com a temática ou com as práticas de design e desenvolvimento. Além disso, há diferentes níveis de participação de um mesmo estudante em diferentes etapas do processo. Questões como estas precisam ser melhor investigadas. Para isto, como trabalhos futuros, pretende-se analisar os níveis de participação dos estudantes por etapa, com atenção especial aos aspectos habilitadores e inibidores da participação infantil nas atividades do projeto. 


\section{Referências}

Brasil (2017) Base Nacional Comum Curricular. Brasília: Ministério da Educação. $<$ http://portal.mec.gov.br/index.php?option=com_docman\&view=download\&alias=7 9601-anexo-texto-bncc-reexportado-pdf-2\&category_slug=dezembro-2017-pdf\&Ite mid=30192> . Acesso em: 2020-03-15.

Caldart, R. S. (2004) Elementos para construção do projeto político e pedagógico da educação do campo. Por uma Educação do Campo, p. 13 - 49.

Caldart, R. S. (2002) Por uma educação do campo: traços de uma identidade em construção. Por uma educação do campo, v. 2, p. 149 - 158.

Caldart, R. S. (2012) Educação do Campo. In: CALDART ISABEL BRASIL PEREIRA, P. A. G. F. R. S. (org.). Dicionário da Educação do Campo. Rio de Janeiro / São Paulo: EPSJV/Expressão Popular. p. 259 - 267.

Molina, M. C. (2014) "Políticas públicas em Educação do Campo: avanços e desafios do PNLD Campo", In: Livro Didático e Educação do Campo, Carvalho, G. T.; Martins, M. F. A, Belo Horizonte/MG, n. 85, p. 25 -34.

Munarim, I. (2014) "As tecnologias digitais nas escolas do campo: contextos, desafios e possibilidades". Tese (Doutorado) - Universidade Federal de Santa Catarina(UFSC).

Morais, D. C. S.; Pontual Falcão, T.; Peres, F. M. A.; Tedesco, P. C. A. R. (2021) Processos de Desenvolvimento Participativo de Tecnologias Digitais Educacionais nos Contextos Urbano e da Educação do Campo. In: Workshop sobre Educação em Computação (WEI), 29, 2021, Evento Online. p. 111-120. ISSN 2595-6175. DOI: https://doi.org/10.5753/wei.2021.15902.

Ortiz, J. S. B.; Pereira, R. (2019) "Ten Years of Initiatives to Promote Computational Thinking: A Systematic Mapping of Literature", In: Journal on Computational Thinking (JCThink), v. 3, n. 1, p. 96, 2019.

Rocha, M. I. A. (2014) O campo e seus sujeitos: desafios para os livros didáticos na educação do campo. Carvalho, G. T.; Martins, M. de F. A. (org.) Livro didático e educação do campo. Belo Horizonte: Faculdade de educação da UFMG, p. 35 - 52.

Santos, S. F., \& Leão, M. F. (2017) "Uso de objetos educacionais digitais para ensinar sistemas do corpo humano em uma escola do campo", In: Revista Brasileira de Educação do Campo, 2(3), 861-880.

Silva, L. M. da et al. (2017) Significados ideológicos do rural brasileiro em fotografias do Programa Nacional do Livro Didático (PNLD-Campo) 2016. Universidade Federal de Uberlândia.

Spinuzzi, C. (2005). The methodology of participatory design. Technical communication, 52(2), 163-174. 